\title{
Reação de Cultivares de Feijão-Caupi à Mela (Rhizoctonia solani) em Roraima
}

\author{
Kátia de Lima Nechet \& Bernardo A. Halfeld-Vieira \\ Embrapa Roraima, Cx. Postal 133, CEP 69301-970, Boa Vista, RR, Brasil, e-mail: katia@cpafrr.embrapa.br
}

Autor para correspondência: Kátia de Lima Nechet

NECHET, K.L. \& HALFELD-VIEIRA, B.A. Reação de cultivares de feijão-caupi à mela (Rhizoctonia solani) em Roraima. Fitopatologia Brasileira 32:424-428. 2007.

\begin{abstract}
RESUMO
Em Roraima, uma das principais doenças que incidem na cultura do feijão-caupi (Vigna unguiculata) é a mela causada pelo fungo Thanatephorus cucumeris (anamorfo Rhizoctonia solani). Este trabalho teve como objetivo avaliar a reação a esta doença de dez cultivares de feijão-caupi em área de cerrado em Roraima, em dois anos consecutivos. As cultivares de porte ereto utilizadas foram BRS-Mazagão, IT86D-719, Vita-7 (Epace-1), BR02-Bragança, Pitiúba, e as de porte prostrado, BRS-Amapá, BR03-Tracuateua, BR17-Gurguéia, BR14-Mulato e Canapuzinho. Os ensaios foram instalados em 2005 e 2006, utilizando-se o delineamento experimental em blocos completos casualizados com cinco tratamentos e quatro repetições. Avaliou-se, semanalmente, a porcentagem de área foliar lesionada para a obtenção da área baixo da curva de progresso da doença. Pelos resultados obtidos verificou-se que os genótipos de porte prostrado apresentaram menor severidade do que os de porte ereto, indicando uma relação da arquitetura da planta com a resistência à mela. As cultivares de porte prostrado, BRS-Amapá, BR03-Tracuateua, BR17-Gurguéia, BR14-Mulato e Canapuzinho, e as de porte ereto, BRS-Mazagão, Pitiúba e BR03-Bragança, foram as mais resistentes à mela e podem ser recomendadas para áreas com histórico de incidência da doença.
\end{abstract}

Palavras-chave adicionais: feijão-de-corda, Thanatephorus cucumeris, Vigna unguiculata.

\begin{abstract}
Reaction of cowpea cultivars to web blight (Rhizoctonia solani) in Roraima, Brazil

Web blight caused by the fungus Thanatephorus cucumeris (Rhizoctonia solani) is one of most important diseases of cowpea (Vigna unguiculata) in the state of Roraima, Brazil. Web blight severity for ten cowpea cultivars was evaluated in Roraima in two consecutive years. The erect cowpea cultivars BRS-Mazagão, IT86D-719, Vita-7 (Epace-1), BR02Bragança and Pitiúba, as well as the prostrate cultivars BRS-Amapá, BR03-Tracuateua, BR17-Gurguéia, BR14-Mulato and Canapuzinho, were used. The experiment was conducted during 2005 and 2006 in a complete randomized block design with five treatments and four replications. The percentage of diseased foliage was evaluated once a week and the data were used to calculate the area under the disease progress curve. Disease severity was lower on prostrate cultivars indicating a relationship between plant architecture and web blight resistance. The prostrate cultivars, BRS-Amapá, BR03-Tracuateua, BR17-Gurguéia, BR14-Mulato and Canapuzinho, and erect cultivars, BRS-Mazagão, Pitiúba and BR03-Bragança, were more resistant to web blight and can be recommended for planting in areas where the disease is known to occur.
\end{abstract}

Additional keywords: Blackeye bean, Thanatephorus cucumeris, Vigna unguiculata.

O feijão-caupi [Vigna unguiculata (L.) Walp.] é uma leguminosa tolerante a grande diversidade de condições de clima e solo, sendo cultivado em escala mundial numa área aproximada de 7 milhões de hectares distribuídos na África, Ásia e Américas (Ehlers \& Hall, 1997). No Brasil, é considerado uma das principais fontes de proteínas para populações de baixa renda das regiões norte e nordeste (Freire Filho et al., 2005). Em Roraima, onde a cultura tem crescido em importância há perspectiva de aumento da área plantada. A produtividade do feijão-caupi neste estado chegou a 1758 kg.ha ${ }^{-1}$ em condições experimentais para genótipos de porte prostrado mostrando uma elevada potencialidade para a cultura (Vilarinho et al., 2005).

A principal doença do feijão-caupi em Roraima é a mela causada pelo fungo Rhizoctonia solani Kühn. Os sintomas da doença são observados inicialmente nas folhas próximas ao solo com manchas de formato irregular que coalescem causando uma necrose e a posterior desfolha das plantas e a adesão das folhas da planta pela teia micelial do fungo. Os sinais são as teias miceliais e os microescleródios formados nos tecidos vegetais (Nechet \& Halfeld-Vieira, 2006). Rhizoctonia solani é um patógeno de solo geneticamente heterogêneo, com ampla gama de hospedeiros, grande capacidade competitiva saprofitica e que sobrevive colonizando restos de cultura ou mediante estruturas de resistência (Cubeta \& Vilgalys, 1997; Papavizas \& Davey, 1961).

Em Roraima, a combinação de temperatura acima de $30^{\circ} \mathrm{C}$ e elevada umidade relativa do ar associada a chuvas freqüentes durante o cultivo do feijão-caupi favorece $o$ desenvolvimento da doença. $\mathrm{Na}$ literatura, as principais medidas de controle recomendadas para a mela do feijão-caupi são evitar o plantio em áreas sujeitas a elevada umidade e a eliminação dos restos de cultura (Sobrinho et al., 2005). O uso de cultivares resistentes representa uma medida de controle 
potencial para a doença principalmente por ser uma opção econômica para os produtores. Entretanto, não há informações na literatura sobre a reação de cultivares de feijão-caupi à mela. O objetivo deste trabalho foi avaliar, nas condições de Roraima, a reação a epifitias espontâneas da mela do feijãocaupi de nove cultivares e uma linhagem de feijão-caupi.

Os experimentos foram instalados em área de Latossolo Amarelo, textura arenosa e topografia plana, no campo experimental Água Boa da Embrapa Roraima, no município de Boa Vista, no estado de Roraima. A época escolhida foi o final do período chuvoso (julho a setembro), nos anos de 2005 e 2006. Os materiais de porte prostrado utilizados nos experimentos foram as cultivares BRS-Amapá, BR03-Tracuateua, BR17-Gurguéia, BR14Mulato e Canapuzinho. Os materiais de porte ereto foram as cultivares BRS-Mazagão, Vita-7 (Epace 1), BR02Bragança, Pitiúba e a linhagem IT86D-719. Dentre estes materiais, a linhagem IT86D-719 e a cultivar Vita-7 eram provenientes do IITA (International Institute of Tropical Agriculture) na Nigéria e as demais eram de origem brasileira (Tabela 1). A área experimental escolhida tinha um histórico consistente por três anos de incidência de mela. $\mathrm{O}$ delineamento experimental utilizado foi de blocos completos casualizados com cinco tratamentos, quatro blocos, sendo cada tratamento constituído por duas parcelas dentro do bloco. Cada parcela foi constituída por quatro linhas de 5 $\mathrm{m}$ de comprimento, espaçadas de $0,5 \mathrm{~m}$ (porte ereto) ou $0,75 \mathrm{~m}$ entre linhas (porte prostrado). As avaliações foram feitas, semanalmente, a partir do $20^{\circ}$ dia após a germinação, totalizando seis avaliações. A porcentagem de área foliar lesionada foi estimada com auxílio da escala diagramática de Van Schoonhoven \& Pastor-Corales (1987) na área útil da parcela, constituída das 20 plantas centrais. A partir dos dados de severidade calculou-se a área abaixo da curva de progresso da doença (AACPD) (Campbell \& Madden, 1990). Os valores de AACPD foram submetidos à análise de variância usando o GLM procedure do software SAS versão 9 (SAS Institute Inc., Cary, USA) e as médias comparadas pelo teste de Fisher LSD a $1 \%$ de probabilidade (Nashimoto \&Wright, 2005). A divergência genética foi estimada por análise de agrupamento a partir dos valores médios de AACPD de cada material nas duas avaliações utilizando-se como medida de dissimilaridade o coeficiente do quadrado da distância euclidiana e método de agrupamento o das médias aritméticas não ponderadas (UPGMA) conforme descrito por Dias (1998) usando o programa Statistica 6.0 (Statsoft Inc., Tulsa, USA).

Observou-se diferença significativa entre a AACPD dos genótipos de porte ereto, tanto em 2005, como em 2006 (Figura 1.I). Em 2005 as cultivares BR02-Bragança $(A A C P D=460)$ e Pitiúba (AACPD=350) apresentaram os menores valores de AACPD enquanto a maior severidade da doença observada para o grupo foi para a linhagem IT86D-719 (AACPD= 695) seguido das cultivares BRS-Mazagão (AACPD $=505$ ) e Vita-7 (Epace-1) $(\mathrm{AACPD}=545)$ (Figura 1.I). No segundo ano de avaliação, os menores valores de AACPD foram observados para as cultivares BR02-Bragança $(\mathrm{AACPD}=241)$
TABELA 1 - Origem, arquitetura e tipo de grão das cultivares de feijão-caupi (Vigna unguiculata) utilizados no estudo de resistência à mela (Rhizoctonia solani)

\begin{tabular}{llll}
\hline \hline Cultivar & Origem & Arquitetura & $\begin{array}{c}\text { Tipo de Grão } \\
\text { (Subcla sse) }\end{array}$ \\
\hline BRS-Mazagão & Brasil & Ereto & Brancão \\
IT86D-719* & Nigéria & Ereto & Branca \\
Vita-7 (Epace-1) & Nigéria & Ereto & Sempre-verde \\
BR02-Bragança & Brasil & Ereto & Manteiga \\
Pitiúba & Brasil & Ereto & Mulato \\
BRS-Amapá & Brasil & Prostrado & Branca \\
BR03-Tracuateua & Brasil & Prostrado & Brancão \\
BR17-Gurguéia & Brasil & Prostrado & Sempre-verde \\
BR14-Mulato & Brasil & Prostrado & Mulato \\
Canapuzinho. & Brasil & Prostrado & Canapu \\
\hline
\end{tabular}

* Linhagem

e BRS-Mazagão (AACPD=253) enquanto novamente a maior severidade incitada pela mela foi para a linhagem IT86D-719 $(\mathrm{AACPD}=739)$ seguida das cultivares Pitiúba $(\mathrm{AACPD}=357)$ e Vita-7 (Epace-1) $(\mathrm{AACPD}=341)$ (Figura 1.I). A cultivar BR02-Bragança e a linhagem IT86D-719 mantiveram a mesma ordem de resistência de um ano para outro, sendo classificadas como a mais resistente e a mais suscetível, respectivamente.

Em 2005 não se observou diferença significativa entre as cultivares de porte prostrado. Os valores de AACPD variaram de 67 (Canapuzinho) a 152 (BR03-Tracuateua) (Figura 1.II). Apenas no segundo ano de avaliação foi detectada diferença entre as cultivares deste grupo. $\mathrm{O}$ menor valor de AACPD foi observado para a cultivar BR03Tracuateua $(\mathrm{AACPD}=112$ ) enquanto a cultivar BRS-Amapá $(\mathrm{AACPD}=311)$ apresentou maior severidade seguida de BR17-Gurguéia (AACPD= 277), Canapuzinho (AACPD= 228) e BR14-Mulato (AACPD $=201)$. (Figura 1.II). Embora tenha sido detectada diferença significativa entre a AACPD das cultivares de porte prostrado no segundo ano de avaliação, esse valores ficaram abaixo de $20 \%$ de severidade ao longo das avaliações.

A matriz de dissimilaridade permitiu agrupar os genótipos em três grupos (Figura 2). As cultivares de porte prostrado e de porte ereto foram agrupadas separadamente e a linhagem IT86D-719 não foi agrupada com as demais. Há uma tendência das cultivares de porte prostrado apresentarem menor severidade de mela quando comparadas com as do grupo de porte ereto. O maior valor de AACPD média do grupo de porte prostrado foi 260 (BRS-Amapá), enquanto que o menor valor de AACPD do grupo de porte ereto foi 350 (BR02- Bragança). A mesma tendência foi observada por Nechet et al. (2006) na seleção de linhagens elites de feijão-caupi resistentes à mela durante ensaios conduzidos em área de cerrado, mata e floresta de transição no estado de Roraima. Segundo os autores, os valores de severidade das linhagens de porte prostrado foram 

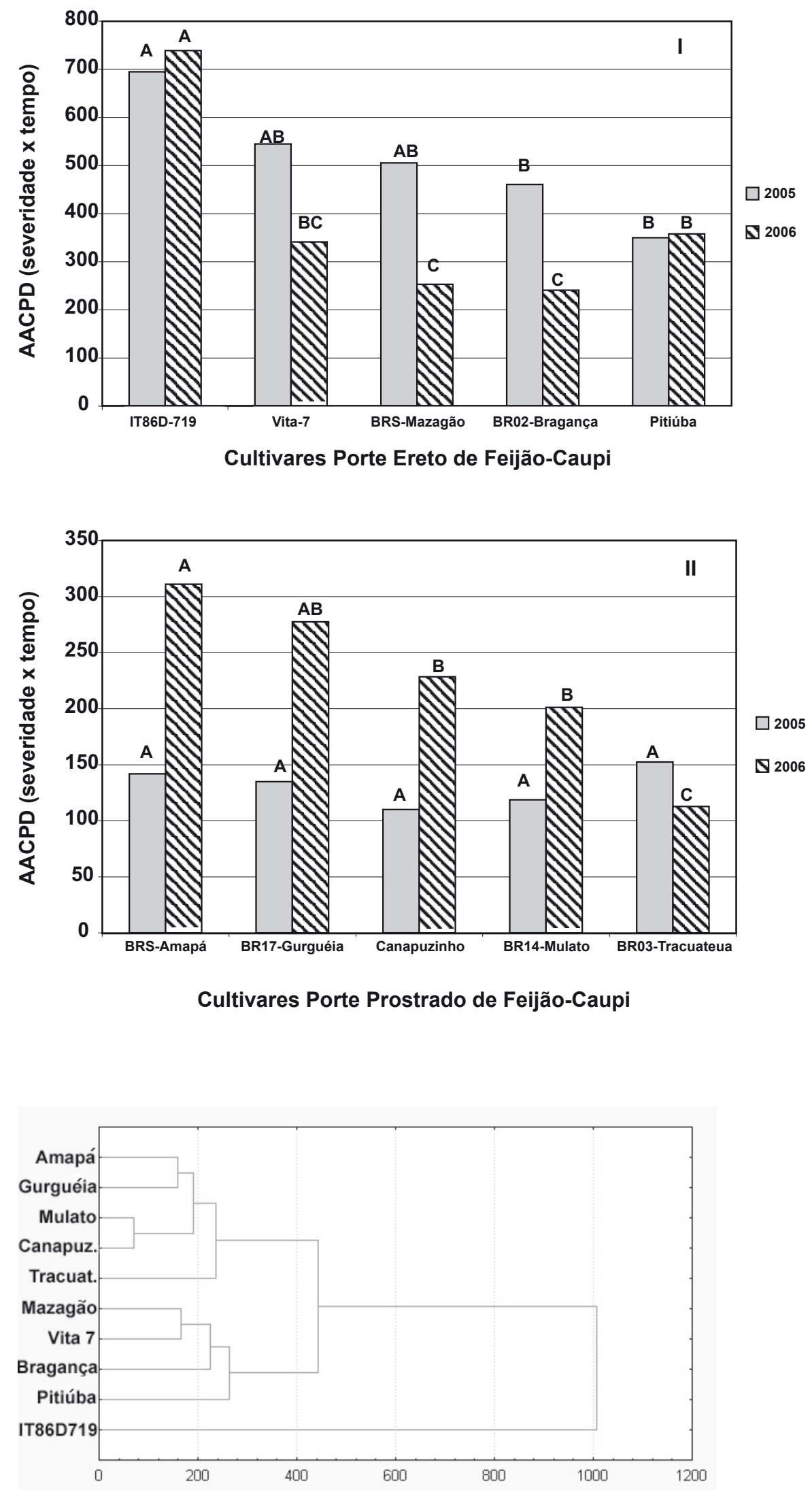

FIG. 1 - Médias da área abaixo da curva de progresso da severidade da mela (AACPD) causada por Rhizoctonia solani em cultivares de porte ereto (I) e prostrado (II) de feijão-caupi (Vigna unguiculata) obtidas em 2005 e 2006. Médias seguidas pela mesma letra entre genótipos por ano não diferem significativamente entre si pelo teste Fisher LSD a 1\%.

FIG. 2- Dendrograma gerado pelo agrupamento UPGMA, construído com base na raiz quadrada da distância euclidiana a partir dos valores médios de dois anos da área abaixo da curva de progresso da severidade da mela (Rhizoctonia solani) em cultivares de feijão-caupi (Vigna unguiculata) de porte ereto e porte prostrado em Roraima. 
inferiores, em todas as avaliações realizadas, aos valores de severidade das linhagens de porte ereto.

O desenvolvimento de plantas de feijão-caupi com arquitetura do tipo ereto é uma tendência em vários países, pois as plantas apresentam ramos mais curtos e são resistentes ao acamamento, possibilitando a colheita mecanizada. Por outro lado, plantas de porte prostrado apresentam ramos inferiores próximos ao solo e pouca tendência a se apoiar em suportes verticais, sendo a colheita manual e escalonada (Freire Filho et al., 2005). A escolha pela arquitetura da planta depende do tipo de colheita a ser adotada pelo produtor. Além das características morfológicas e fenológicas das plantas de feijãocaupi, a resistência a patógenos é um parâmetro importante avaliado nos programas de melhoramento (Ehlers \& Hall, 1997).

Oyekan et al. (1976), em estudo conduzido nas condições da Nigéria, verificaram que dentre 51 linhagens de feijão-caupi, apenas três foram classificadas como resistentes à mela. Elawad \& Singh (2003) relatam a resistência múltipla da cultivar "Dahab Elgoz" a várias doenças, incluindo a mela. No presente estudo, a linhagem IT86D-719 não se mostrou adequada para ser utilizada como parental nos programas de melhoramento visando resistência à mela, apesar de ser recomendada para a África por apresentar alta produtividade (Singh, 2006).

Além da variabilidade fenotípica do feijãocaupi para arquitetura de planta e tipo de grão, outros estudos mostram reações diferenciadas de cultivares para resistência a viroses (Lima et al., 2001), cercosporiose (Castro et al., 2003) e à sarna (Barreto et al., 2001). Não existem registros anteriores da variabilidade de cultivares de feijão-caupi para resistência à mela no Brasil. Os resultados obtidos neste trabalho indicam haver uma relação de tipo de arquitetura com a resistência à doença. O mecanismo de defesa das plantas de porte prostrado deve ser investigado, buscando identificação de genes de resistência à mela que possam ser transferidos para plantas de porte ereto.

Considerando as cultivares avaliadas, nas condições testadas, as de porte prostrado são as mais indicadas para áreas com incidência de mela, e dentre as de porte ereto recomendam-se BRSMazagão, Pitiúba e BR03-Bragança como resistentes à doença.

\section{AGRADECIMENTOS}

Os autores agradecem ao Conselho Nacional de Desenvolvimento Científico e Tecnológico - CNPq pelo apoio financeiro ( Proc. 471038/2006-7).

\section{REFERÊNCIAS BIBLIOGRÁFICAS}

BARRETO, P.D., SANTOS, A.A., VIDAL, J.C., QUINDERÉ, M.A.W. \& SÁ, M F.P. Reação de genótipos de Vigna unguiculata à sarna e efeito da doença sobre componentes de produção. Fitopatologia Brasileira 26:5-9. 2001.

CAMPBELL, C.L. \& MADDEN, L.V. Introduction to plant disease epidemiology. New York NY. Wiley. 1990.

CASTRO, N.R., MENEZES, G.C. \& COELHO, R.S.B. Herança da resistência genética do caupi à cercosporiose. Fitopatologia Brasileira 28:552-554. 2003.

CUBETA, M.A. \& VILGALYS, R. Population biology of the Rhizoctonia solani complex. Phytopathology 87:480-484. 1997.

DIAS, L.A. Análises multidimensionais. In: Alfenas, A.C. (Ed.) Eletroforese de Isoenzimas e Proteínas afins. Viçosa. UFV. 1998. pp. 405-475.

EHLERS, J.D. \& HALL, A.E. Cowpea (Vigna unguiculata L. Walp.). Fields Crop Research 53:187-204. 1997.

ELAWAD, H.O.A. \& SINGH, B.B. Registrations of "Dahab Elgoz" cowpea. Crop Science 43: 1880. 2003.

FREIRE FILHO, F.R., LIMA, J.A. A. \& RIBEIRO, V.Q. FeijãoCaupi. Avanços Tecnológicos. Brasília DF. Embrapa Informação Tecnológica. 2005.

LIMA, J.A.A., MARREIROS, E.O., FREIRE FILHO, F., SITTOLIN, I.M. \& RIBEIRO, V.Q. Fontes de resistência múltipla em feijão-caupi a vírus das famílias Bromoviridae, Comoviridae e Potyviridae. Fitopatologia Brasileira 26(Supl):521. 2001.

NECHET, K.L. \& HALFELD-VIEIRA, B.A. Caracterização de isolados de Rhizoctonia spp., associados à mela do feijãocaupi (Vigna unguiculata), coletados em Roraima. Fitopatologia Brasileira 31:505-508. 2006.

NECHET, K.L., VILARINHO, A.A. \& HALFELD-VIEIRA, B.A. Reação de genótipos de feijão-caupi a mela (Rhizoctonia solani) em três ecossistemas de Roraima. Anais. Congresso Nacional de Feijão-Caupi. Teresina PI. 2006. CD-ROM.

NASHIMOTO, K. \& WRIGHT, F.T. Multiple comparison procedures for detecting differences in simply ordered means. Computational Statistics and Data Analysis 48:291-306. 2005.

OYEKAN, P.O., ONESIROSAN, P.T. \& WILLIAMS, R.J. Screening for resistance in cowpea to web blight. Tropical Grain Legume Bulletin 3:6-8. 1976.

PAPAVIZAS, G.C. \& DAVEY, C.B. Saprophytic behavior of Rhizoctonia in soil. Phytopathology 51:693-699. 1961.

SINGH, B.B. Cowpea breeding at IITA: highlights of advances and impacts. Anais. Congresso Nacional de Feijão-Caupi. Teresina PI. 2006. CD-ROM.

SOBRINHO, C.A., VIANA, F.M.P. \& SANTOS, A.A. Doenças fúngicas e bacterianas. In: Freire Filho, F.R., Lima, J.A.A. \& Ribeiro, V.Q. (Eds.) Feijão-Caupi. Avanços Tecnológicos. Brasília DF. Embrapa Informação Tecnológica. 2005. pp. 463497.

VAN SCHOONHOVEN, A. \& PASTOR-CORALES, M.A. Sistema estándar para la evaluación de germoplasma de frijol. Cali. CIAT. 1987. 
VILARINHO, A.A., FREIRE FILHO, F.R., ROCHA, M. M., RIBEIRO, V.Q. \& VILARINHO, L.B.O. Adaptabilidade e estabilidade de linhagens de feijão caupi (Vigna unguiculata
(L.) Walp.) de porte prostrado em Roraima. Anais. $3^{\circ}$ Congresso Brasileiro de Melhoramento de Plantas. Gramado RS. 2005. CD-ROM.

Recebido 18 Dezembro 2006 - Aceito 17 Setembro 2007 - FB 6141 